\title{
THE CHEK2 del5395 IS A FOUNDER MUTATION WITHOUT DIRECT EFFECTS FOR CANCER RISK IN THE LATVIAN POPULATION
}

\author{
Plonis $\mathrm{J}^{*}$, Kalniete D, Nakazawa-Miklasevica M, Irmejs A, Vjaters E, Gardovskis J, Miklasevics E
}

*Corresponding Author: Juris Plonis, M.D., Institute of Oncology, Riga Stradins University, Dzirciema 16, LV1007, Riga, Latvia. Tel: +371-2915-9476. Fax:+371-6706-9904. E-mail: juris.plonis@inbox.lv

\begin{abstract}
Our objective was to determine: 1$)$ whether the checkpoint kinase 2 (CHEK2) del5395 (g.2741711327422508 del, NC_000022.11) is a founder mutation in the Latvian population, 2) if there is an association between CHEK2 del5395 mutation and cancer risk, and 3) and whether the CHEK2 del5395 mutation impacts cancer predisposition in Chernobyl disaster liquidators (the civil and military personnel who were called upon to deal with consequences of the 1986 nuclear disaster) as well as geriatric populations. We recruited 438 breast cancer patients, 568 colorectal cancer patients, 399 ovarian cancer patients, 419 prostate cancer patients, 526 healthy blood donors, 480 Chernobyl disaster liquidators and 444 geriatric cancer-free participants. DNA samples were isolated from blood samples and subjected to multiplex polymerase chain reaction (PCR). The truncation of del5395 was estimated by fragment size of the multiplex PCR. All groups were compared to the healthy blood donors using Fisher's exact test. All $p$ values were two-sided and the odds ratios (OR) calculated by two-by-two table. In cancer groups, the del5395 mutation was most frequently observed in the ovarian cancer group $(1.00 \%, \mathrm{OR}=1.32)$. In control groups, the del5395 mutation was most frequent $(0.76 \%)$ in the healthy donors, which exceeded its frequency in the Chernobyl liquidators group and the geriatric group by 0.01 and $0.08 \%$, respectively. For all groups,
\end{abstract}

\footnotetext{
* Institute of Oncology, Riga Stradins University, Riga, Latvia
}

the OR appeared to be $>1$ only in ovarian cancer patients. However, OR rates showed no statistical significance in either cancer or control groups, with the $p$ value fluctuating within the range of 0.39-1.00. The CHEK2 gene del5395 is a founder mutation in the Latvian population, which, however, does not have a direct impact on genetic predisposition toward colorectal, breast, ovarian and prostate cancer.

Keywords: Cancer; Checkpoint kinase 2 (CHEK2) gene; Chernobyl disaster liquidators; del5395.

\section{INTRODUCTION}

Checkpoint kinase 2 (CHEK2) phosphorylates P53 and BRCA1 proteins at a checkpoint of doublestranded DNA break signal transduction pathway to cell cycle control, apoptosis and DNA repair [1]. Walsh et al. [2] were the first to report a big truncation mutation of CHEK2 del5395 (g.2741711327422508del, NC_000022.11) in the Czech and Slovak Republics' patients with a family history of breast cancer. Similar to further studies carried out in Poland, the del5395 mutation can also be found in the Polish population, so it was assumed to be an Eastern European founder mutation [3]. The frequency of the del 5395 mutation among Czech, Slovak and Polish populations is $0.9-1.3 \%$ [2-4].

The association between del5395 and cancers is still to be established. According to Cybulski et al. [4], the presence of the del5395 mutation increased the odds ratio (OR) of breast cancer development to 
2.0. However, in another Polish study by Myszka et al. [5], no associations between del5395 and breast cancer development was found. In cases of colorectal cancer, Cybulski et al. [6] observed no association between the del5395 mutation and increased cancer risk, while the missense mutation I157T was found to play a role in cancer development. Presence of the del 5395 mutation is associated with an increased prostate cancer risk [3]. On the other hand, the CHEK2 mutations, including de15395, decrease the risk of lung and laryngeal cancers [7].

Most of the del5395 research is based on the Polish population. Thus, due to the lack of studies conducted in other Eastern European countries, we undertook to find out the following: 1) whether the del5395 is a founder mutation in the Latvian population, 2) if there is an association between CHEK2 de15395 mutation and a cancer risk, and 3) and whether CHEK2 del5395 mutation impacts cancer predisposition in Chernobyl disaster liquidators (the civil and military personnel who were called upon to deal with consequences of the 1986 nuclear disaster) as well as geriatric populations.

\section{MATERIALS AND METHODS}

Patients and Control Groups. From 2010 to 2012, we recruited random groups of volunteers consisting of 438 breast cancer patients, negative for both the BRCA1 (4153delA and insC5382) and BRCA2 (886delTG and 873delG) founder mutations; 568 colorectal cancer patients; 399 ovarian cancer patients; and 419 prostate cancer patients diagnosed at the Pauls Stradins University Hospital, the Latvian Oncology Centre, Riga, Latvia and the Daugavpils Oncology Hospital, Daugavpils, Latvia. Control groups consisted of 526 healthy blood donors, 480 Chernobyl disaster liquidators and 444 geriatric cancer-free participants. All participants signed the informed consent form. The study was approved by the Pauls Stradins University Hospital Ethics Committee.

DNAAnalysis. DNA samples were isolated from blood samples and subjected to multiplex polymerase chain reaction (PCR). Multiplex PCR was performed using previously described primer pairs [3]. The truncation of del5395 was identified by multiplex PCR. Briefly, two primer pairs were used for genotyping of a large deletion of exons 9 and 10. The first pair flanked a breakpoint site in intron 8. The second pair flanked a breakpoint site in intron 10. In mutationnegative cases, only two PCR fragments of 379 and $522 \mathrm{bp}$ were amplified from the wild-type allele. The forward primer of the first pair and the reverse primer of the second pair amplified an additional PCR product of $450 \mathrm{bp}$ in mutation-positive cases. The presence of the deletion was confirmed by sequencing.

Statistical Analysis. All cancer patient groups, Chernobyl disaster liquidators and the geriatric group were compared to the healthy blood donors using Fisher's exact test. All $p$ values were two-sided and OR was calculated by two-by-two table. Software program R Bioconductor (http://www.bioconductor. org) was used for all statistical analyses.

\section{RESULTS}

In cancer groups, the de15395 mutation was most frequently observed in the ovarian cancer group with a frequency of $1.00 \%[\mathrm{OR}=1.32 ; 95 \%$ confidence interval (CI) 0.24-7.13; $p=0.73$ ), whereas in cases of prostate cancer its frequency was the lowest $0.24 \%$ $(\mathrm{OR}=0.31 ; 95 \%$ CI 0.06-3.7; $p=0.39)$ (Table 1$)$. As far as the control groups are concerned, the healthy donors' group was marked by the most frequent de15395 mutation $(0.76 \%)$, whereas its frequency in the Chernobyl liquidators group and the geriatric group was $0.83 \%(\mathrm{OR}=1.09 ; 95 \%$ CI $0.20-5.90 ; p=1.0)$ and $0.68 \%(\mathrm{OR}=0.89 ; 95 \%$ CI $0.13-5.28 ; p=1.0)$, respectively (Table 1). For both the cancer and control groups OR appeared to be $>1$ only in ovarian cancer patients. However, OR rates showed no statistical significance in either cancer or control groups, with the $p$ value fluctuating within the range of 0.39-1.00.

\section{DISCUSSION}

Results obtained in this study support the assumption that del5395 is a founder mutation in the Eastern European population, although statistically significant relationship between the del5395 mutation and cancers risks could not be established. The frequency of del5395 in breast cancer patients $(0.68 \%)$ was slightly lower than that reported in Poland $[4,5]$, Czech Republic and Slovakia [2], whereas in ovarian cancer patients $(1.0 \%)$ it was similar to that in the above reports. However, higher frequency of del5395 in the healthy control group significantly lowered the 
Table 1. The frequencies of the del5395 mutation in cancer and control groups.

\begin{tabular}{|l|c|c|c|c|c|c|c|}
\hline & \multicolumn{2}{|c|}{ Age } & $\begin{array}{c}\text { del5395 } \\
\text { Mutation }\end{array}$ & $\begin{array}{c}\text { Frequency } \\
(\%)\end{array}$ & OR & 95\% CI & $p$ Value \\
\hline Cancer Groups & Mean & Range & & & & & \\
\hline Colorectal & 67 & $18-88$ & $2 / 568$ & 0.35 & 0.46 & $0.04-3.23$ & 0.43 \\
\hline Breast & 62 & $28-89$ & $3 / 435$ & 0.68 & 0.90 & $0.13-5.35$ & 1.00 \\
\hline Ovarian & 57 & $16-86$ & $4 / 399$ & 1.00 & 1.32 & $0.24-7.13$ & 0.73 \\
\hline Prostate & 66 & $42-91$ & $1 / 419$ & 0.24 & 0.31 & $0.06-3.70$ & 0.39 \\
\hline Total & 63 & $16 / 91$ & $10 / 1824$ & 0.55 & 0.75 & $0.28-1.94$ & 0.52 \\
\hline Control Groups & & & & & & & - \\
\hline Healthy donors & 35 & $18-65$ & $4 / 524$ & 0.76 & - & & - \\
\hline Chernobyl liquidators & 53 & $33-75$ & $4 / 480$ & 0.83 & 1.09 & $0.20-5.90$ & 1.00 \\
\hline Geriatric patients & 73 & $60-97$ & $3 / 444$ & 0.68 & 0.89 & $0.13-5.28$ & 1.00 \\
\hline Total & 53 & $18-97$ & $11 / 1450$ & 0.73 & & & \\
\hline
\end{tabular}

OR: odds ratio; $95 \% \mathrm{CI}$ : 95\% confidence interval.

OR of each cancer group in this study. The Chernobyl liquidators had been exposed to high radiation that had caused DNA damage and higher cancer development risk [8].

Radiation is one of the factors activating the CHEK2 protein. In response to DNA damage, the CHEK2 protein interacts with several other proteins, including tumor protein 53 (that is produced from the TP53 gene). These proteins halt cell division and determine whether a cell will repair the damage or self-destruct in a controlled manner (undergo apoptosis). This process keeps cells with mutated or damaged DNA from dividing, thus helping to prevent the development of tumors [1].

It was assumed that the $C H E K 2$ mutation carriers would be more sensitive to ionizing radiation and thus have a higher predisposition towards cancer development. Of the 51 cancer patients with different types of cancer in the Chernobyl liquidators group in this study $(9.6 \%)$, none had the del5395 mutation. The geriatric control group was designed to estimate the strength of the del5395 mutation against mortality. If del5395 correlates with an increase in the rates of oncological diseases and mortality in the population, the geriatric group should have lower frequency of de15395. Nevertheless, we did not observe any statistically significant difference in the frequency of de15395 between the healthy control group and the geriatric group $(\mathrm{OR}=0.89 ; 95 \% \mathrm{CI} 0.13-5.28 ; p=1)$. In the 51 Chernobyl liquidators with different localization of cancers, the del5395 mutation was not identified (data not shown).
We concluded that the CHEK2 gene del5395 is a founder mutation in the Latvian population, which, however, does not have a direct impact on genetic predisposition toward colorectal, breast, ovarian and prostate cancer. Moreover, we believe that the de15395 mutation requires further research to identify additional genetic and/or environmental factors, which in combination with the above mutation, increase the odds of cancer development.

Declaration of Interest. This study was supported by the State research program "Biomedicine for Public Health (BIOMEDICINE)." The authors report no conflicts of interest. The authors alone are responsible for the content and writing of this article.

\section{REFERENCES}

1. Bartek J, Lukas J. Chk1 and Chk2 kinases in checkpoint control and cancer. Cancer Cell. 2003; 3(5): 421-429.

2. Walsh T, Casadei S, Coats KH, Swisher E, Stray SM, Higgins J, et al.. Spectrum of mutations in BRCA1, BRCA2, CHEK2, and TP53 in families at high risk of breast cancer. JAMA. 2006; 295(12): 1379-1388.

3. Cybulski C, Wokołorczyk D, Huzarski T, Byrski $\mathrm{T}$, Gronwald J, Górski B, et al. A large germline deletion in the Chek2 kinase gene is associated with an increased risk of prostate cancer. J Med Genet. 2006; 43(11): 863-866. 
4. Cybulski C, Wokołorczyk D, Huzarski T, Byrski $\mathrm{T}$, Gronwald J, Górski B, et al. A deletion in CHEK2 of 5,395 bp predisposes to breast cancer in Poland. Breast Cancer Res Treat. 2007; 102(1): 119-122.

5. Myszka A, Karpinski P, Slezak R, Czemarmazowicz H, Stembalska A, Gil J, et al. Irrelevance of CHEK2 variants to diagnosis of breast/ovarian cancer predisposition in Polish cohort. J Appl Genet. 2011; 52(2): 185-191.

6. Cybulski C, Wokołorczyk D, Cybulski C, Wokołorczyk D, Kładny J, Kurzawski G, et al. Germline CHEK2 mutations and colorectal cancer risk: Different effects of a missense and truncating mutations. Eur J Hum Genet. 2007; 15(2): 237-241.
7. Cybulski C, Masojc B, Oszutowska D, Jaworowska E, Grodzki T, Waloszczyk P, et al. Constitutional CHEK2 mutations are associated with a decreased risk of lung and laryngeal cancers. Carcinogenesis. 2008; 29(4): 762-765.

8. Eglite ME, Zvagule TJ, Rainsford KD, Reste JD, Curbakova EV, Kurjane NN. Clinical aspects of the health disturbances in Chernobyl Nuclear Power Plant accident clean-up workers (liquidators) from Latvia. Inflammo-pharmacology. 2009; 17(3): 163-169. 